\title{
Characterisation of a proposed Nucleorhabdovirus new to South Africa
}

\author{
R. L. Lamprecht ${ }^{1}$, G. Pietersen ${ }^{1,2}$, G. G. F. Kasdorf ${ }^{3}$ and L. H. Nel $^{1}$
}

(1) Department of Microbiology and Plant Pathology, Faculty of Natural and Agricultural Sciences, University of Pretoria, Pretoria, 0002, South Africa

(2) Citrus Research International, University of Pretoria, Pretoria, 0002, South Africa

(3) Agricultural Research Council-Plant Protection Research Institute Pretoria, Pretoria, 0002, South Africa

L. H. Nel

Email: louis.nel@up.ac.za

\section{Abstract}

A previously uncharacterised plant rhabdovirus, infecting Bermuda grass (Cynodon dactylon) in the North West Province, South Africa, has been found. To determine the morphology and virion size of this virus, embedded ultra-thin sections of infected plant samples were observed under a transmission electron microscope. The virion distribution within the cell, its bullet-shaped morphology and its size $(240 \times 63 \mathrm{~nm})$ indicated that this might be a rhabdovirus of the genus Nucleorhabdovirus. Degenerate polymerase chain reaction (PCR) primers were designed by alignment of the polymerase gene sequences of several plant rhabdoviruses in order to identify conserved regions. Standard PCR and sequencing protocols were used to determine a partial polymerase gene sequence of this virus sample which was then compared to the most closely related sequences available on Genbank. The analysis indicated that the virus was indeed most closely related to known nucleorhabdoviruses, with the highest nucleotide sequence similarities being to Maize mosaic virus and Taro vein chlorosis virus (70\% and $69.7 \%$ respectively). Serological testing indicated that the South African Cynodon rhabdovirus had a close serological relationship with the nucleorhabdovirus Cynodon chlorotic streak virus.

\footnotetext{
Abbreviations

AMV Avian myoblastosis virus - CCSV Cynodon chlorotic streak virus - dNTP deoxynucleotide triphosphate - L gene Polymerase gene - LNYV Lettuce necrotic yellows virus - MMV Maize mosaic virus - NCMV Northern cereal mosaic virus - OFV Orchid fleck virus - RYSV Rice yellow stunt virus - SCV Strawberry crinkle virus SYNV Sonchus yellows net virus - TaVCV Taro vein chlorosis virus - TMV Tobacco mosaic virus - U Units - UHQ Ultra high quality water
} 
The Rhabdoviridae family, of the order Mononegavirales, contains a large number of viruses that are of human and veterinary public health and agricultural importance as members of this virus family can infect a broad spectrum of plants, vertebrates and invertebrates (Jackson et al. 2005; Dietzgen et al. 2006). There are six recognised rhabdovirus genera, being Vesiculovirus, Lyssavirus, Ephemerovirus, Novirhabdovirus and the two plant virus genera, Cytorhabdovirus and Nucleorhabdovirus (Fauquet et al. 2005). Kondo et al. (2006) proposed a new plant rhabdovirus genus Dicorhabdovirus, after sequencing the full genome of a proposed new rhabdovirus with a bipartite genome, Orchid fleck virus (OFV) (Kondo et al. 2006). The two recognised plant rhabdovirus genera are separated according to where the virus particles replicate, that is in the cytoplasm or in the nucleus. There are more than 100 rhabdoviruses described worldwide that still need to be classified and it is widely realised that many rhabdoviruses remain to be discovered (Kuzmin et al. 2006; Fauquet et al. 2005). In the past, most putative plant rhabdoviruses have been recognised by their characteristic bullet-shaped or bacilliform particles and many have been described based only on electron microscopy. To date, only seven recognised plant rhabdoviruses have been completely sequenced. More nucleotide sequence data from plant rhabdoviruses is needed for definite identification and classification, and also to broaden knowledge and understanding of the epidemiology of plant rhabdoviruses (Reed et al. 2005; Jackson et al. 2005).

Rhabdoviruses have a single-stranded, negative sense RNA genome that encodes five functional proteins: the nucleoprotein $(\mathrm{N})$, the phosphoprotein $(\mathrm{P})$, the matrix protein $(\mathrm{M})$, the glycoprotein $(\mathrm{G})$ and the polymerase (L). However, to date all the fully sequenced plant rhabdoviruses have an additional open reading frame between the $\mathrm{P}$ and M genes (Jackson et al. 2005; Bourhy et al. 2005; Heim et al. 2008). There are six blocks of known amino acid sequence conservation in the $\mathrm{L}$ protein of the rhabdoviruses. The blocks of conservation were designated blocks I-VI, of which blocks II-V, located in the central region of the L protein, have relative high amino acid conservation. Block III of the polymerase protein has the highest amino acid conservation and is conserved among all RNA-dependent RNA polymerases (Poch et al. 1990; Bourhy et al. 2005).

Bermuda grass (Cynodon dactylon) is a perennial species of the family Poaceae with a worldwide distribution (Hosseini and Izadpanah 2005). Rhabdovirus-like particles were found to be associated with chlorotic streak symptoms in Cynodon dactylon in Morocco in 1974 and the virus, named Cynodon chlorotic streak virus (CCSV), was found to be widely distributed in the Mediterranean area (Lockhart et al. 1985). Similar chlorotic streak symptoms were found in Bermuda grass in the North West Province of South Africa in 1995 and such plants also contained rhabdovirus-like particles. The aim of the study was to characterise this virus on the basis of antigenicity and genetic sequence comparisons. Utilising the conserved regions of the L gene, degenerate RT-PCR primers were designed and subsequent analysis of the amplified sequence indicated that this virus was most closely related to the group of viruses within the genus Nucleorhabdovirus. Antisera specific to CCSV (Lockhart et al. 1985) reacted with the South African virus in 
ISEM analyses and confirmed a close relationship between the two viruses. This report is the first to describe the presence of a nucleorhabdovirus in South Africa.

Symptomatic bermuda grass, believed to be infected with an unidentified virus, was vegetatively propagated and maintained in a greenhouse at the University of Pretoria (Pretoria, South Africa). Fresh leaf samples were taken whenever needed. To determine the morphology and virion size, embedded ultra-thin sections of infected plant material were observed under a Philips EM301 transmission electron microscope as described by Van Der Merwe and Coetzee (1992). Tobacco mosaic virus (TMV) was used as an external standard to calibrate magnifications. Viral RNA was extracted from infected plant material using SV Total RNA Isolation System (Promega, Wisconsin) according to the method described by the manufacturers. ClustalW in BioEdit version 7.0.0 (Hall 1999) was used to perform a multiple alignment of the L gene of various Nucleo- and Cytorhabdoviruses available on Genbank (Table 1). Degenerate primers were designed to the most conserved regions of the $\mathrm{L}$ genes and were expected to be broadly reactive to plant rhabdoviruses. For cDNA synthesis, $10 \mu$ l Cynodon rhabdovirus-infected total plant RNA and $1 \mu \mathrm{RhabF}(10 \mathrm{pmol})$ were denatured at $70^{\circ} \mathrm{C}$ for $5 \mathrm{~min}$ and cooled on ice for 2 min. A mixture of $40 \mathrm{U}$ Avian myoblastosis virus (AMV) reverse transcriptase (RT), 40 $\mathrm{mM}$ dNTPs, $50 \mathrm{U}$ RNase Inhibitor and AMV buffer (Roche, Switzerland) was added to the reaction tube, and made up to $20 \mu \mathrm{l}$ with ultra high quality DNAse and RNAse free water (UHQ water) and incubated at $25^{\circ} \mathrm{C}$ for $10 \mathrm{~min}$. The temperature was then increased to $42^{\circ} \mathrm{C}$ and incubation at this temperature was for $1 \mathrm{~h}$. The AMV RT was then inactivated at $99^{\circ} \mathrm{C}$ for $5 \mathrm{~min}$. PCR reactions of $50 \mu \mathrm{l}$ reaction volumes were prepared. The reaction mixture consisted of $5 \mu \mathrm{l}$ of $10 \times$ reaction buffer (Bioline, UK), $50 \mathrm{mM}$ $\mathrm{MgCl}_{2}, 40 \mathrm{mM}$ dNTPs, 10 pmol of each primer, and 2.5U Taq polymerase (Bioline, UK). Finally $5 \mu \mathrm{l}$ of the cDNA template was added, and the volume made up to $50 \mu \mathrm{l}$ with UHQ water. The cycle conditions, on a ABI GeneAmp PCR System 2700 (PE Applied Biosystems, Connecticut), were as follows: one cycle at $94^{\circ} \mathrm{C}$ for $2 \mathrm{~min}$, and then 30 cycles of $94^{\circ} \mathrm{C}$ for $30 \mathrm{~s}, 37^{\circ} \mathrm{C}$ for $30 \mathrm{~s}, 72^{\circ} \mathrm{C}$ for $90 \mathrm{~s}$, followed by one final cycle at $72^{\circ} \mathrm{C}$ for $7 \mathrm{~min}$.

Amplicons were analysed on a 1\% agarose gel with a O'GeneRuler 100 bp DNA Ladder Plus (Fermentas, Vilnius Lithuania) and viewed under a UV transilluminator (Vilber Lourmat, France). A Strawberry crinkle virus (SCV) clone was kindly supplied by M. Goodin (University of Kentucky, Lexington) and was used as a positive control in PCR reactions. For cloning, PCR products were ligated into pGEM-T Easy Vector (Promega, Wisconsin) and the recombinant plasmids introduced into JM109 High Efficiency Competent Cells according to the manufacturer's instructions (Promega, Wisconsin) (Sambrook and Russel 2001). Cloned inserts were sequenced in both directions using RhabF and RhabR primers (see below). The sequencing reactions were performed using ABI Prism BigDye Primer Cycle Sequencing Kits (PE Applied Biosystems, Connecticut), according to the manufacturer's specifications. Sequencing was with an automated fluorescent sequencer (ABI 377 DNA Sequencer, PE Applied Biosystems, Connecticut) at the University of Pretoria's commercial sequencing facility. Consensus sequences from forward and reverse primers derived from a single clone were created with the ContigExpress option from Vector NTI Advance 9. The sequences were 
analysed by using the basic local alignment search tool (BLAST) programme available on the National Centre for Biotechnology Information website (http://ncbi.nlm.nih.gov/). The Cynodon rhabdovirus partial L gene sequence was compared with all available polymerase gene sequences of cytorhabdoviruses and nucleorhabdoviruses by doing multiple alignments with ClustalX in BioEdit version 7.0.0 (Hall 1999). Mega Version 3.1 (Kumar et al. 2004) was used to construct a neighbour-joining phylogenetic tree based on the cognate sequence regions. Antiserum, raised against CCSV in rabbits, was kindly supplied by Lockhart (Lockhart et al. 1985). Crude undiluted plant sap from infected Bermuda grass was used as antigen in an ISEM assay as follows: for trapping of the virus particles, different dilutions $\left(1: 100\right.$ or 1:1,000 vv $\left.{ }^{-1}\right)$ of the CCSV antisera, in phosphate buffer $(0.02 \mathrm{M}, \mathrm{pH} 7)$, were placed onto dental wax. Freshly carbon-coated Formvar clad grids were placed on the drops and left for $1 \mathrm{~h}$ at room temperature. The grids were washed with phosphate buffer $(0.02 \mathrm{M}, \mathrm{pH} 7)$ and each of the grids was placed on a drop of crude plant sap extracts and left for $1 \mathrm{~h}$ at $37^{\circ} \mathrm{C}$. After another washing step, the grids were placed onto another set of antiserum dilutions $\left(1: 10\right.$ or $\left.1: 100 \mathrm{vv}^{-1}\right)$ for particle decoration, and incubated for $1 \mathrm{~h}$ at $37^{\circ} \mathrm{C}$. Staining of the grids with uranyl acetate for 5 min was followed with a final washing step with phosphate buffer as well as ddH20. Pre-immunisation serum prepared in rabbits was used as a negative control, in the same dilutions as mentioned above. The grids were viewed under an EM 002A ABT transmission electron microscope. Viral particles were counted to examine the enrichment of the particle trapping by the CCSV antiserum relative to the trapping by the pre-immune serum.

Table 1 L gene sequences of plant rhabdoviruses available on Genbank used for primer design

\section{Acc. number}

\begin{tabular}{|l|l|}
\hline \multicolumn{2}{|l|}{ Nucleorhabdovirus } \\
\hline Sonchus yellow net virus (SYNV) & L32603 \\
\hline Taro vein chlorosis virus (TaVCV) & AY674964 \\
\hline Rice yellow stunt virus (RYSV) & AB001125 \\
\hline Maize mosaic virus (MMV) & AY618418 \\
\hline Cytorhabdovirus & \\
\hline Lettuce necrotic yellows virus (LNYV) & NC007642 \\
\hline Northern cereal mosaic virus (NCMV) & NC002251 \\
\hline Strawberry crinkle virus (SCV) & AY250986 \\
\hline
\end{tabular}

The abbreviation as well as the accession number of each of these viruses is also listed Vegetatively propagated Bermuda grass samples, showing fine chlorotic streaking along the leaf veins, were sampled from the greenhouse of the University of Pretoria (Pretoria, South Africa) for electron microscopic analysis. Transmission electron micrographs of ultrathin sections of these samples were used to determine the intercell distribution as well as the morphology of this virus. The virions were found to be present in the nucleus 
of infected cells and were present in high numbers (Fig. 1a). The viral particles were mostly bullet-shaped, and bacilliform particles were occasionally observed. It was apparent that size variation between individual particles was minimal, and 69 individual particles were measured, using TMV for external calibration of the electron micrographs. The sizes of the virions were found to be typical for members of the Rhabdoviridae family (Jackson et al. 2005) and were on average: $240 \mathrm{~nm}( \pm 26)$ in length and $60 \mathrm{~nm}$ $( \pm 6.5)$ in width (Fig. 1b).
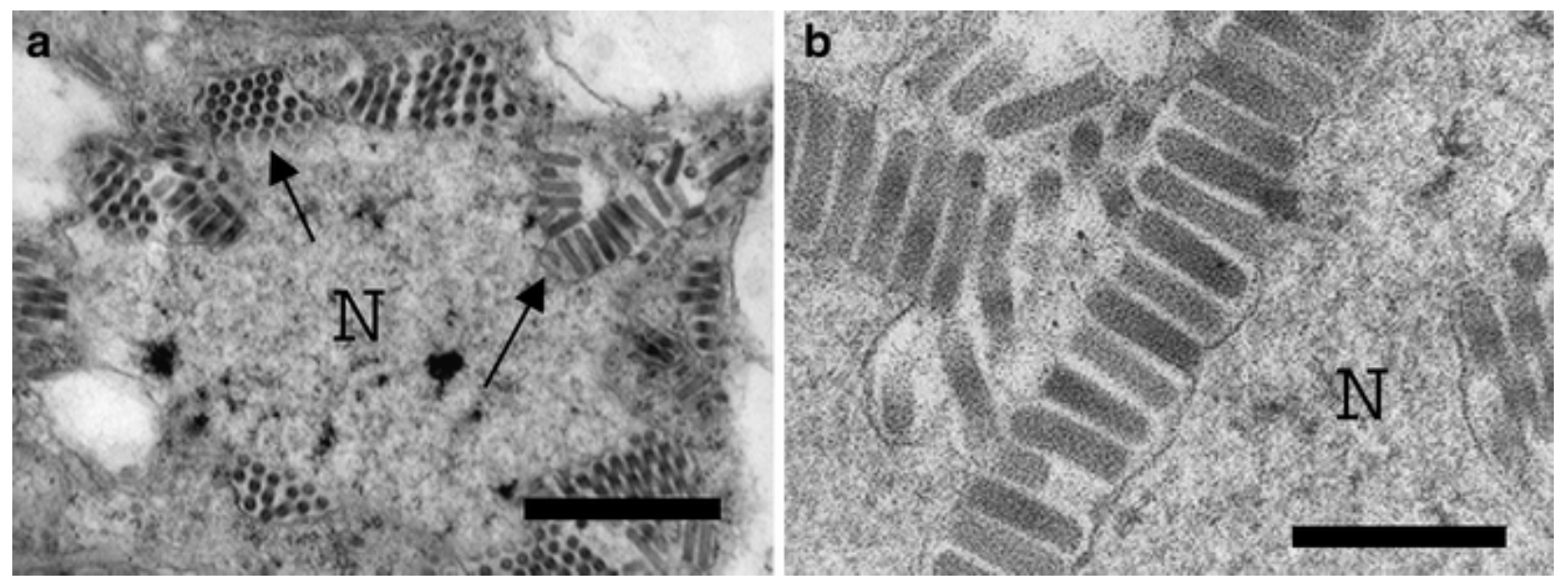

Fig. 1 a Transmission electron micrograph indicating the Cynodon rhabdovirus virions in the nucleus $(\mathrm{N})$. The arrows indicate viral particles that are in the process of budding through the nuclear envelope. Scale bar $=1 \mu \mathrm{m}$. b Transmission electron micrograph showing the typical bullet-shaped virion particles of the Cynodon rhabdovirus. Nucleus $(N)$ indicated. Scale bar $=300 \mathrm{~nm}$

For RT-PCR, conserved areas of known plant rhabdovirus L genes were targeted and degenerate primers were designed from blocks I and III of the aligned L genes. For two or more mismatches, the site was considered degenerate and the primers were: forward primer RhabF (5'-GGATMTGGGGBCATCC-3'), designed from block I; reverse primer RhabR (5'-GTCCABCCYTTTTGYC-3'), designed from block III. The expected amplicon from this primer set was approximately $900 \mathrm{bp}$ depending on rhabdovirus species detected. RT-PCR was carried out with primers RhabF and RhabR on total RNA extracted from symptomatic Bermuda grass. The amplicons obtained with this primer set represented a 900 bp segment from both the Cynodon sample and SCV. The PCR product was purified from the gel and cloned into pGEM-T Easy Vector, and sequenced from both directions utilising RhabF and RhabR. A contiguous sequence was produced and yielded a $791 \mathrm{bp}$ fragment. BLAST analysis confirmed that the cloned inserts were of viral RNA (polymerase gene) origin and that it was most closely related to sequences of various nucleorhabdovirus polymerase genes. The obtained sequence was submitted to GenBank (accession number EU650683).

The 791 bp sequenced fragment of the putative new Cynodon rhabdovirus was aligned with the L gene of known plant rhabdoviruses available on Genbank. For phylogenetic 
analysis, a $732 \mathrm{bp}$ region of this alignment of the Cynodon rhabdovirus and selection of other plant rhabdoviruses was used. Pairwise distances were calculated and phylogenetic trees constructed as described. The Cynodon rhabdovirus had the highest homology to the nucleorhabdoviruses Maize mosaic virus (MMV) and Taro vein chlorosis virus (TaVCV). Phylogenetically the panel of viruses could be divided into two distinct clades, correlating with the Cyto- and Nucleorhabdovirus genera (Fig. 2). The putative new Cynodon rhabdovirus grouped within the nucleorhabdovirus clade, where it was close to, but distinct from MMV.

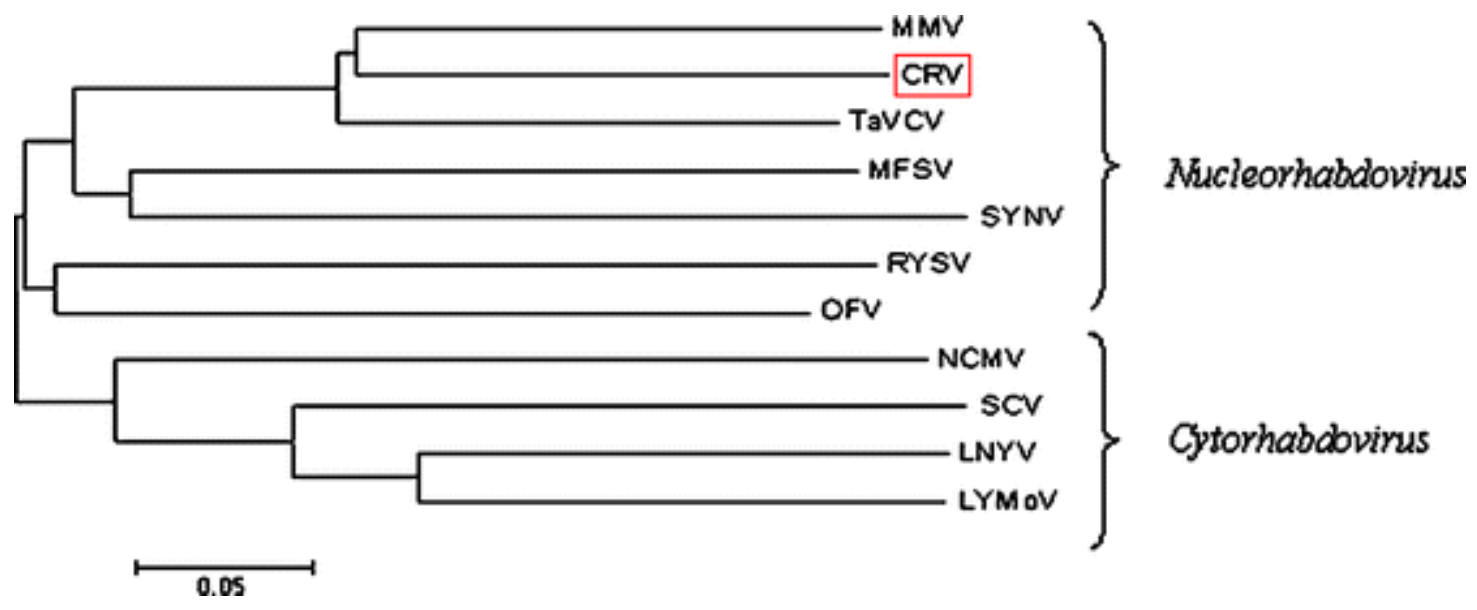

Fig. 2 Phylogenetic tree of partial L gene nucleic sequences of Cynodon rhabdovirus (CRV) and other plant rhabdoviruses [TaVCV (AY674964), LNYV (NC007642), MMV (AY618418), NCMV (NC002251), RYSV (AB001125), SCV (AY250986), MFSV (AY618417), SYNV (L32603), OFV (NC009609) and LYMoV (EF687738)). The tree was constructed using MEGA 3.1 using the bootstrap neighbour-joining method (Kumar et al. 2004)

The antiserum raised against CCSV from Morocco reacted with the Cynodon rhabdovirus from South Africa, and decorated the Cynodon rhabdovirus particles in a dark halo, indicating a close serological relationship between CCSV and the South African Cynodon rhabdovirus. Counting of the trapped viral particles (at 1:100 serum dilutions $\left.v v^{-1}\right)$ indicated that the CCSV antisera resulted in $23.2( \pm 3.96)$ particles whereas the pre-immune serum only yielded particle counts of $6.6( \pm 2.88)$.

We report the presence and identification of a bullet-shaped virus found in high numbers in the cell nuclei of infected Cynodon dactylon grass in South Africa. From our morphological, serological and sequence data, we concluded that this virus is a putative Nucleorhabdovirus from the family Rhabdoviridae and our report constitutes the first record of the presence of a member of this genus in South Africa.

Sequence analysis indicated that this Cynodon rhabdovirus was most closely related to the nucleorhabdovirus MMV. From the literature, however, a nucleorhabdovirus of Cynodon, CCSV, was reported in 1985 and was found to be widely spread throughout the 
Mediterranean area (Lockhart et al. 1985). These authors also described the relatedness of CCSV and MMV. Unfortunately, CCSV has never been analysed on sequence level and no sequence data for this virus is available in the public domain. The source of the virus was however lost and therefore the sequences of the two viruses could not be compared at molecular level (B. E. L. Lockhart, personal communication). Although there appears to be slight differences in the particle sizes we have observed $(240 \times 60 \mathrm{~nm})$ and that reported for CCSV $(280 \times 80 \mathrm{~nm})$, our Cynodon rhabdovirus was found to be closely related to CCSV, based on serology. Based on our cumulative evidence of morphology, pathology, serology and phylogeny, it is likely that our Cynodon rhabdovirus is CCSV or a strain of CCSV. Since no sequence information is available for CCSV, this suggestion is speculative and indeed; sequence data is required to establish the true taxonomic status of the virus known as CCSV. Since sequence data of only seven other recognised plant rhabdoviruses and three unclassified plant rhabdoviruses are available in the public domain, our contribution of the first sequence data from a Cynodon nucleorhabdovirus is also the first of any Nucleorhabdovirus from South Africa and adds to what should be a growing sequence database for these globally disseminated plant pathogens.

Planthoppers and leafhoppers are common insect vectors for Nucleorhabdoviruses, and it is very likely that this is the case for the Cynodon rhabdovirus. MMV is transmitted by the leafhopper Peregrinus maidis. However, the vector for TaVCV is still unknown but is suspected that it is transmitted by the planthopper Tarophagus proserpina (Revill et al. 2005). The degenerate primers as well as the established RT-PCR protocol used in this study can be utilised to determine the vector species responsible for the horizontal transfer of the Cynodon rhabdovirus. The protocols used in this study could also be utilised as tools for detecting known, as well as new, plant rhabdoviruses in field studies, broadening our understanding about the epidemiology of these viruses and addressing the problem of inconclusive classification and taxonomy. At present, it is not clear whether the South African Cynodon rhabdovirus poses any threat to the significant maize farming industry of southern Africa.

\section{References}

Bourhy, H., Cowly, J. A., Larrous, F., Holmes, E. C., \& Walker, P. J. (2005).

Phylogenetic relationships among rhabdoviruses inferred using the L polymerase gene.

Dietzgen, R. G., Callaghan, B., Wetzel, T., \& Dale, J. L. (2006). Completion of the genome sequence of Lettuce necrotic yellows virus, type species of the genus Cytorhabdovirus. Virus Research, 118, 16-22.

Fauquet, C. M., Mayo, M. A., Maniloff, J., Desselberger, U. \& Ball L. A. (Eds.) (2005). Virus taxonomy: VIIIth Report of the International Committee on Taxonomy of Viruses (pp 213-228). New York: Elsevier. 
Hall, T. A. (1999). BioEdit: a user-friendly biological sequence alignment editor and analysis program for Windows 95/98/NT. Nucleic Acids Symposium Series, 41, 95-98.

Heim, F., Lot, H., Delecolle, B., Bassler, A., Krezal, G., \& Wetzel, T. (2008). Complete nucleotide sequence of a putative new cytorhabdovirus infecting lettuce. Archives of Virology, 153, 81-92.

Hosseini, A., \& Izadpanah, K. (2005). Biological, serological and physicochemical properties of Bermuda grass filamentous viruses from Iran. Parasitica, 61, 55-59.

Jackson, A. O., Dietzgen, R. G., Goodin, M. M., Bragg, J. N., \& Deng, M. (2005). Biology of plant rhabdoviruses. Annual Review of Phytopathology, 43, 623-660.

Kondo, H., Maeda, T., Shikaro, Y., \& Tamada, T. (2006). Orchid fleck virus is a rhabdovirus with an unusual bipartite genome. Journal of General Virology, 87, 24132421.

Kumar, S., Tamura, K., \& Nei, M. (2004). MEGA3: Integrated software for Molecular Evolutionary Genetics Analysis and sequence alignment. Briefings in Bioinformatics, 5, $150-153$.

Kuzmin, I. J., Hughes, G. J., \& Rupprecht, C. E. (2006). Phylogenetic relationships of seven previously unclassified viruses within the family Rhabdoviridae using partial nucleoprotein gene sequences. Journal of General Virology, 87, 2323-2331.

Lockhart, B. E. L., Khaless, N., El Maataoui, M., \& Lastra, R. (1985). Cynodon chlorotic streak virus, a previously undescribed plant rhabdovirus infecting Bermuda grass and maize in the Mediterranean area. Phytopathology, 75, 1094-1098.

Poch, O., Blumberg, B. M., Bougueleret, L., \& Tordo, N. (1990). Sequence comparison of five polymerases (L proteins) of unsegmented negative-strand RNA viruses: theoretical assignment of functional domains. Journal of General Virology, 71, 11531162.

Reed, S. E., Tsai, C. W., Willie, K. J., Redinbaugh, M. G., \& Hogenhout, S. A. (2005). Shotgun sequencing of the negative-sense RNA genome of the rhabdovirus Maize mosaic virus. Journal of Virological Methods, 129, 91-96.

Revill, P., Trihn, X., Dale, J., \& Harding, R. (2005). Taro vein chlorosis virus: characterization and variability of a new nucleorhabdovirus. Journal of General Virology, 86, 491-499. 
Sambrook, J. \& Russel, D. W. (2001). Molecular cloning. A laboratory manual (3rd ed.). Cold Spring Harbor, New York: Cold Spring Harbor Laboratory.

Van der Merwe, C. F., \& Coetzee, J. (1992). Quetol 651 for general use: a revised formulation. Proceedings of the Electron Microscopy Society of South Africa, 22, 31-32. 